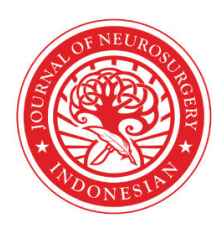

\section{Effect of hyperglycemia at admission on the outcome of surgical evacuation of supratentorial spontaneous intracerebral hemorrhage}

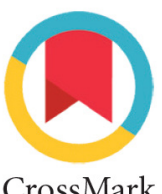

CrossMark

\author{
Mohamad Saekhu ${ }^{1 *}$, Hilman Mahyuddin ${ }^{1}$, Samsul Ashari ${ }^{1}$, David Tandian ${ }^{1}$, Hanif G Tobing ${ }^{1}$, \\ Renindra A Aman', Syaiful Ichwan' ${ }^{1}$, Wismaji Sadewo', Setyowidi Nugroho'
}

\title{
ABSTRACT
}

Introduction: Spontaneous intracerebral hemorrhage $(\mathrm{SICH})$ has a high mortality rate. Factors that affect outcomes include hematoma volume and hyperglycemia. Evacuation of hematoma reduces mortality. This study aimed to validate the effect of hyperglycemia at admission on the outcome of surgical evacuation of supratentorial SICH.

Methods: This study is part of a clinical trial that assessed the neuroprotective effects of tigecycline. The association between patient variables and in-hospital mortality and length of hospital stay (LOS) was analyzed using the chi-square test and Fisher's exact test. Logistic regression was conducted to identify the independent predictors of outcome.
Results: Approximately $65 \%$ of patients with supratentorial SICH were hyperglycaemic. The factors associated with hyperglycaemia were brain midline shift (MLS) (odds ratio [OR]: 14.5; 95\% confidence interval $[\mathrm{CI}]: 1.8-117.3 ; \mathrm{p}=0.002)$ and history of diabetes (OR: $7.7 ; 95 \% \mathrm{Cl}: 0.9-63.6 ; \mathrm{p}=0.045)$. Hyperglycaemia was a predictor of MLS (OR: $0.074,95 \% \mathrm{Cl}: 0.009-0.613 ; p=0.016)$ and was not significantly associated with in-hospital mortality (OR: 2.6; $95 \% \mathrm{Cl}: 0.7-8.9 ; \mathrm{p}=0.126)$ and $\mathrm{LOS}>15$ days (OR: $0.9 ; 95 \%$ Cl: $0.3-2.7 ; p=0.898)$.

Conclusion: Hyperglycemia was not associated with in-hospital mortality and LOS in patients with supratentorial SICH.

Keywords: Hyperglycemia, LOS, mortality, SICH

Cite This Article: Saekhu, M.m Mahyuddin, H., Ashari, S., Tandian, D., Tobing, H.G. Aman, R.A., Ichwan, S., Sadewo, W., Nugroho, S. 2020. Supratentorial extra parenchymal schwannoma mimicking meningioma: a case report. Indonesian Journal of Neurosurgery 3(2): 44-47. D0I: 10.15562/ijn.v3i2.82

'Department of Neurosurgery, Faculty of Medicine, Universitas Indonesia, Cipto Mangunkusumo Hospital, Jakarta, Indonesia
*Corresponding author: Mohamad Saekhu; Department of Neurosurgery, Faculty of Medicine, Universitas Indonesia, RSUP Nasional Dr. Cipto Mangunkusumo, Jakarta, Indonesia; m.saekhu@ui.ac.id
Received: 2019-09-16

Accepted: 2019-11-20 Published: 2020-02-20

\section{INTRODUCTION}

The case fatality of spontaneous intracerebral hemorrhage (SICH) is high, particularly in low- to middle-income countries. ${ }^{1,2}$ The 1-month mortality of such condition is $40 \%,{ }^{3}$ and no significant change was observed within the last two decades. ${ }^{4}$ Aside from hematoma volume, comorbidities are the significant factors that influence mortality and outcome $\mathrm{e}^{5-7}$, of which hyperglycemia is the most common. ${ }^{8}$ Clinical studies have shown that hyperglycemia in the acute phase of ischaemic and hemorrhagic stroke is associated with poor outcome. ${ }^{8,9}$ Meanwhile, other studies have shown that surgical evacuation of hematoma can reduce mortality. ${ }^{7}$ Therefore, the detrimental effect of hyperglycemia on the outcome of patients with SICH who are undergoing surgical evacuation of hematoma must be further validated. This study aimed to assess the effect of hyperglycemia on in-hospital mortality and length of hospital stay (LOS) in patients with supratentorial SICH who underwent surgical evacuation of the hematoma.

\section{METHODS}

This study is a subanalysis (cohort design) from the previous clinical trial that assessed the neuroprotective effects of tigecycline. ${ }^{10}$ The ethical clearance number of the study of the neuroprotective effects of tigecycline was 493/PT02.FK/ETIK/2012. Out of 72 subjects, 68 subjects had the result of blood glucose level at admission to the hospital, and four subjects were missed the blood glucose levels. Only subjects who had blood glucose levels at admission are included in this study.

The blood glucose levels of the subjects were assessed before the administration of prophylactic antibiotics. Based on blood glucose levels, subjects were divided into hyperglycemia and non-hyperglycemia groups. Hyperglycaemia was defined as blood glucose level $>140 \mathrm{mg} / \mathrm{dL}$ (7.77 $\mathrm{mmol} / \mathrm{L})^{11}$

We also collect data that previously believed to affect the outcome of patients with SICH. The outcomes measured included in-hospital mortality and LOS. Data about LOS were dichotomized to 
Table 1. Baseline characteristics of the participants

\begin{tabular}{|c|c|c|c|c|}
\hline \multirow{2}{*}{\multicolumn{2}{|c|}{ Variables }} & \multicolumn{2}{|c|}{$\begin{array}{c}\text { Blood glucose level } \geq 140 \\
\mathrm{mg} / \mathrm{dL}(\mathrm{n}=68)\end{array}$} & \multirow[t]{2}{*}{ p value } \\
\hline & & Yes & No & \\
\hline \multicolumn{5}{|l|}{ Age } \\
\hline & $\geq 60$ years & 9 & 4 & \multirow{2}{*}{$1^{*}$} \\
\hline & $<60$ years & 35 & 20 & \\
\hline \multicolumn{5}{|c|}{ Sex } \\
\hline & Female & 18 & 7 & \multirow{2}{*}{0.337} \\
\hline & Male & 26 & 17 & \\
\hline \multicolumn{5}{|l|}{ GCS } \\
\hline & $>8$ & 26 & 19 & \multirow{2}{*}{0.094} \\
\hline & $\leq 8$ & 18 & 5 & \\
\hline \multicolumn{5}{|c|}{ Hematoma volume } \\
\hline & $\geq 50 \mathrm{~mL}$ & 26 & 12 & \multirow{2}{*}{0.471} \\
\hline & $<50 \mathrm{~mL}$ & 18 & 12 & \\
\hline \multicolumn{5}{|l|}{ MLS } \\
\hline & $\geq 10 \mathrm{~mm}$ & 17 & 1 & \multirow{2}{*}{0.002} \\
\hline & $<10 \mathrm{~mm}$ & 27 & 23 & \\
\hline \multicolumn{5}{|c|}{ OAC } \\
\hline & Yes & 36 & 17 & \multirow{2}{*}{0.296} \\
\hline & No & 8 & 7 & \\
\hline \multicolumn{5}{|c|}{ History of hypertension } \\
\hline & Yes & 40 & 21 & \multirow{2}{*}{0.691} \\
\hline & No & 4 & 3 & \\
\hline \multicolumn{5}{|c|}{ History of diabetes } \\
\hline & Yes & 11 & 1 & \multirow{2}{*}{$0.045^{*}$} \\
\hline & No & 33 & 23 & \\
\hline \multicolumn{5}{|c|}{ MABP } \\
\hline & $\geq 127$ & 22 & 9 & \multirow{2}{*}{0.323} \\
\hline & $<127$ & 22 & 15 & \\
\hline \multicolumn{5}{|c|}{ Leukocyte count (cells/mm³) } \\
\hline & $\geq 11.000$ & 35 & 16 & \multirow{2}{*}{0.274} \\
\hline ? & $<11.000$ & 8 & 7 & \\
\hline \multicolumn{5}{|c|}{ Administration of tigecycline } \\
\hline & Yes & 22 & 11 & \multirow{2}{*}{0.743} \\
\hline 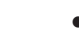 & No & 22 & 13 & \\
\hline
\end{tabular}

GCS $=$ Glasgow Coma Scale, MABP $=$ mean arterial blood pressure, MLS $=$ midline shift, OAC $=$ obliteration of ambient cisterns. ${ }^{*}=$ Fisher's exact test
$<15$ days based on our clinical experience. We assessed for the severity of clinical injury using the Glasgow Coma Scale, and radiologic severity was examined according to hematoma volume, degree of brain midline shift (MLS), and obstruction of the ambient cistern. ${ }^{12,13}$ Midline shift (MLS) was measured at the level of the foramen of Monro using the following equation: MLS $=(\square / 2)-\square$, where a is the width of the intracranial space through the septum pellucidum (SP), and $\mathrm{b}$ is the distance from the bone to the SP. ${ }^{13}$

The chi-square test and Fisher's exact test were used to analyze the association between the characteristics of patients, radiological findings, and outcomes. A multivariate analysis using logistic regression was conducted for variables with a p-value $<0.25$ in the univariate analysis. A p-value $<0.05$ was considered statistically significant.

\section{RESULTS}

The mean age of the subjects in this study was $54.5 \pm 9$ years, the mean volume of hematoma was $51 \pm 15 \mathrm{~mL}$, and the mean blood sugar level at admission was $173 \pm 64 \mathrm{mg} / \mathrm{dL}$. The proportion of hyperglycemia on various factors that were commonly believed to affect the outcome of $\mathrm{SICH}$ seen in Table 1.

The multivariate analysis with logistic regression showed that MLS was a predictor of hyperglycemia (odds ratio [OR]: 0.074; 95\% confidence interval [CI]: 0.009-0.613; $\mathrm{p}=0.016)$.

A total of 19 (26\%) in-hospital mortalities were recorded during the study, and 15 (79\%) patients died within the first seven days after surgery. The median LOS was 12.5 (range: 2 - 64) days. The effect of hyperglycemia on the outcome of surgical evacuation of supratentorial $\mathrm{SICH}$ is shown in Table 2.

Patients with hyperglycemia upon admission did not significantly differ in terms of in-hospital mortality and LOS.

Table 2. Association between outcomes and blood glucose

\begin{tabular}{|c|c|c|c|c|c|}
\hline \multirow{2}{*}{ Outcomes } & \multicolumn{2}{|c|}{$\begin{array}{l}\text { Blood glucose levels upon } \\
\text { admission }\end{array}$} & \multirow[t]{2}{*}{ p-value } & \multirow[t]{2}{*}{$\begin{array}{c}\text { RR } \\
(95 \% \mathrm{Cl})\end{array}$} & \multirow[t]{2}{*}{$\begin{array}{c}\text { OR } \\
(95 \% \mathrm{Cl})\end{array}$} \\
\hline & $\begin{array}{c}>140 \mathrm{mg} / \mathrm{dL} \\
(\mathrm{n}, \%)\end{array}$ & $\begin{array}{c}\leq 140 \mathrm{mg} / \mathrm{dL} \\
(\mathrm{n}, \%)\end{array}$ & & & \\
\hline In-hospital mortality & $15(34)$ & $4(17)$ & 0.126 & $\begin{array}{c}1.26 \\
(0.958-1.67)\end{array}$ & $\begin{array}{c}2.59 \\
(0.747-8.95)\end{array}$ \\
\hline LOS $\geq 15$ days & $14(32)$ & $8(33)$ & 0.898 & $\begin{array}{c}0.978 \\
(0.691-1.384)\end{array}$ & $\begin{array}{c}0.933 \\
(0.323-2.693)\end{array}$ \\
\hline
\end{tabular}

Note: $\mathrm{OR}=$ odds ratio, $\mathrm{RR}=$ relative risk, $95 \% \mathrm{CI}=95 \%$ confidence interval, $\mathrm{LOS}=$ length of hospital stay. ${ }^{*}$ Fisher's exact test 


\section{DISCUSSION}

Hyperglycaemia is a common medical complication in patients with SICH. Pathophysiologically, hyperglycemia is caused by the disruption of blood glucose regulation in the brainstem due to the mass effect of hematoma and brain herniation. ${ }^{12}$ Previous studies have shown that the prevalence of hyperglycemia in patients with SICH is $51 \% .{ }^{13}$ Although a higher cut-off value was used to define hyperglycemia $(7.77 \mathrm{mmol} / \mathrm{L}$ rather than $6.5 \mathrm{mmol} / \mathrm{L}$ ), this study showed a higher prevalence of $65 \%$. This phenomenon may be attributed to three reasons. First, one study of traumatic brain injury has shown that patients with more severe injury have significantly higher blood glucose levels. ${ }^{14}$ MLS was associated with hyperglycemia in our study, which strengthens the notion that such a condition can reflect the severity of brain injury correlated to SICH. Second, all patients in our study had a hematoma volume $>30 \mathrm{~mL}$, compared with $<30 \mathrm{~mL}$ in other studies. ${ }^{10,13}$ Third, the prevalence of diabetes in our study was higher than that of previous studies (18\% vs. $11 \%$ ). Following a previous study, ${ }^{13}$ our study showed that a history of diabetes was significantly associated with hyperglycemia (OR: 7.667; 95\% CI: 0.925 - 63.567; $\mathrm{p}=0.045$ ).

Considering that hyperglycemia can reflect the severity of brain injury in patients with SICH, such a condition can affect the outcome of patients with SICH. Previous studies have shown that hyperglycemia is associated with mortality after SICH. ${ }^{13,15,16}$ In contrast, our study showed that hyperglycemia upon admission was not associated with mortality and LOS. Indeed, all participants in our study underwent hematoma evacuation, whereas participants in previous studies did not. Hematoma volume is considered a determinant factor for outcome. ${ }^{5}$ Hematoma evacuation may negate the influence of other factors. Another study that included both surgical and non-surgical patients has shown that hyperglycemia did not affect mortality. ${ }^{17}$

The present study had some limitations. The outcome upon discharge and in-hospital mortality and LOS are challenging to assess. However, after five days of managing patients with supratentorial $\mathrm{SICH}$, early assessment of the prognosis of SICH is feasible, ${ }^{18}$ and the adverse effect of hyperglycemia can be observed within the first four weeks after onset. ${ }^{19}$ Also, short-term assessments, such as evaluation of in-hospital mortality and LOS, can be used to distinguish patients who may benefit from the surgical evacuation of hematoma and to provide information about recovery expectations to patients and relatives. ${ }^{20}$

\section{CONCLUSION}

The prevalence of hyperglycemia in patients with supratentorial SICH is approximately $65 \%$. The mass effect of hematoma is associated with hyperglycemia. However, in-hospital mortality and LOS are not affected by hyperglycemia upon admission.

\section{Acknowledgments}

We thank all patients and their families who participated in this study, and hospitals were included in this study with their permission.

\section{AUTHOR CONTRIBUTIONS}

MS conceived and carried out the experiments, involved in treating patients who are research subjects, and wrote the manuscript. HM conceived the experiments. SA supervised the project. DT involved in treating patients who are research subjects. HGT involved in treating patients who are research subjects. SI involved in treating patients who are research subjects. WS involved in treating patients who are research subjects. SN supervised the project.

\section{CONFLICT OF INTEREST}

The authors declare that there is no conflict of interest regarding the publication of this study.

\section{FUNDING}

No funding

\section{REFERENCES}

1. Ferrete-Araujo AM, Egea-Guerrero JJ, Vilches-Arenas A, Godoy AD, Murillo-Cabezas F. Predictors of mortality and poor functional outcome in severe spontaneous intracerebral hemorrhage: A prospective observational study. Med Intensiva. 2015; 39(7): 422 - 32. DOI: 10.1016/j. medin.2014.10.008.

2. An SJ, Kim TJ, Yoon B-W. Epidemiology, risk factors, and clinical features of intracerebral hemorrhage: an update. $J$ Stroke. 2017; 19(1): 3 - 10. DOI: 10.5853/jos.2016.00864.

3. Van Asch CJ, Luitse MJ, Rinkel GJ, van der Tweel I, Algra A, Klijn CJ. Incidence, case fatality, and fuctional outcome of intracerebral haemorrhage over time, according to age, sex, and ethnic origin: a systematic review and meta-analysis. Lancet Neurol. 2010; 9(2): 167 - 76. DOI: 10.1016/S14744422(09)70340-0.

4. Carlsson M, Wilsgaard T, Johnsen SH, Vangen-Lonne AM, Lochen M-L, Njolstad I, et al. Temporal trends in incidence and case fatality of intracerebral hemorrhage: the Tromso study 1995-2012. Cerebrovasc Dis Extra. 2016; 6(2): 40 - 9. DOI: $10.1159 / 000447719$.

5. Safatli DA, Gunther A, Schlattmann P, et al. Predictor of 30 day mortality in patients with spontaneous primary intracerebral hemorrhage. Surg Neurol Int 2016;7:S510-7. 
6. Lee S-H, Park K-J, Kang S-H, Jung Y-G, Park J-Y, Park D-H. Prognostic factors of clinical outcomes in patients with spontaneous thalamic hemorrhage. Med Sci Monit. 2015; 21: 2638 - 46. DOI: 10.12659/MSM.894132.

7. Patil CG, Alexander AL, Gephart MGH, Lad SP, Arrigo RT, Boakye M. A population-based study of inpatient outcomes after operative management of nontraumatic intracerebral hemorrhage in the United States. World Neurosurg. 2012; 78(6): 640 - 5. DOI: 10.1016/j.wneu.2011.10.042.

8. Koivunen RJ, Haapaniemi E, Satopaa J, Niemela M, Tatlisumak T, Putaala J. Medical acute complications of intracerebral hemorrhage in young adults. Stroke Res Treat. 2015: 357696. DOI: $10.1155 / 2015 / 357696$.

9. Chen R, Ovbiagele B, Feng W. Diabetes and stroke: epidemiology, pathophysiology, pharmaceuticals and outcomes. Am J Med Sci. 2016; 351(4): 380 - 6. DOI: 10.1016/j.amjms.2016.01.011.

10. Saekhu M, Mahyuddin H, Ronokusumo TAS, Sastroasmoro S. Tygecycline reduced tumor necrosis factor alpha level and inhospital mortality in spontaneous supratentorial intracerebral hemorrhage. Med J Indones. 2016; 25(2): 69 75. DOI: $10.13181 / \mathrm{mji} . v 25 i 2.1351$.

11. Viana MV, Moraes RB, Fabbrin AR, Santos MF, Gerchman F. Assessment and treatment of hyperglycemia in critically ill patients. Rev Bras Ter Intensiva. 2014; 26(1): 71 - 6. DOI: 10.5935/0103-507X.20140011.

12. Sun C, Liao W, Jiang W, Gao P, Pan W. The pathophysiology mechanism and treatment of secondary brain insult of hypertensive intracerebral hemorrhage. Integr Med Int. 2017; 4(3-4): 107 - 14. DOI: 10.1159/000481728.

13. Saxena A, Anderson CS, Wang X, Sato S, Arima H, Chan E, et al. Prognostic significance of hyperglycemia in acute intracerebral hemorrhage. The INTERACT2 study. Stroke. 2016; 47(3): 682 - 8. DOI: 10.1161/ STROKEAHA.115.011627.

14. Rau C-S, Wu S-C, Chen Y-C, Chien P-C, Hsieh H-Y, Kuo P-J, et al. Stress-induced hyperglycemia, but not diabetic hyperglycemia, is associated with higher mortality in patients with isolated moderate and severe traumatic brain injury: analysis of a propensity score-matched population. Int J Environ Res Public Health. 2017; 14(11): 1340. DOI: 10.3390/ijerph14111340.

15. Sun S, Pan Y, Zhao X, Liu L, Li H, He Y, et al. Prognostic value of admission blood glucose in diabetic and nondiabetic patients with intracerebral hemorrhage. Sci Rep. 2016; 6: 32342. DOI: 10.1038/srep32342.

16. Snarska KK, Bachorzewska-Gajewska H, KapicaTopczewska K, Drozdowski W, Chorazy M, Kulakowska A, et al. Hyperglycemia and diabetes have different impacts on outcome of ischemic and hemorrhagic stroke. Arch Med Sci. 2017; 13(1): 100 - 8. DOI: 10.5114/aoms.2016.61009.

17. Kongwad LI, Hedge A, Menon G, Nair R. Influence of admission blood glucose in predicting outcome in patients with spontaneous intracerebral hematoma. Front Neurol. 2018; 9: 725. DOI: 10.3389/fneur.2018.00725.

18. Maas MB, Francis BA, Sangha RS, Lizza BD, Liotta EM, Naidech AM. Refining prognosis for intracerebral hemorrhage by early reassessment. Cerebrovasc Dis. 2017; 43(3-4): 110 - 116. DOI: 10.1159/000452679.

19. Fogelholm R, Murros K, Rissanen A, Avikainen S. Long term survival after primary intracerebral hemorrhage: a restrospective population based study. J Neurol Neurosurg Psychiatry. 2005; 76(11): 1534 - 8. DOI: 10.1136/ jnnp.2004.055145.

20. Ariesen M, Algra A, van der Worp HB, Rinkel G. Applicability and relevance of models that predict short term outcome after intracerebral hemorrhage. $J$ Neurol Neurosurg Psychiatry. 2005; 76(6): 839 - 44. DOI: 10.1136/ jnnp.2004.048223.

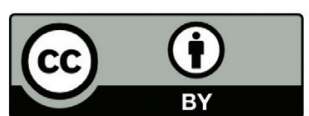

This work is licensed under a Creative Commons Attribution 